\title{
2 Dimensional Hydrodynamic Flood Routing Analysis on Flood Forecasting Modelling for Kelantan River Basin
}

\author{
Wan Hazdy Azad ${ }^{1,2, a}$, Lariyah Mohd Sidek ${ }^{1}$, Hidayah Basri ${ }^{1}$, Chow Ming Fai ${ }^{1}$, Suhani Saidin ${ }^{1}$ and Abd. Jalil Hassan ${ }^{3}$ \\ ${ }^{1}$ Centre for Sustainable Technology \& Environment (Centre for Energy Infrastructure) Universiti Tenaga Nasional, Jalan IKRAM- UNTEN \\ 43000 Kajang, Selangor, Malaysia \\ ${ }^{2}$ Department of Irrigation and Drainage, KM7 Jalan Ampang, 68000 Kuala Lumpur, Malaysia \\ ${ }^{3}$ River Net Consulting Sdn. Bhd., Seksyen 32, 40460 Shah Alam, Selangor, Malaysia
}

\begin{abstract}
Flood disaster occurs quite frequently in Malaysia and has been categorized as the most threatening natural disaster compared to landslides, hurricanes, tsunami, haze and others. A study by Department of Irrigation and Drainage (DID) show that $9 \%$ of land areas in Malaysia are prone to flood which may affect approximately 4.9 million of the population. 2 Dimensional floods routing modelling demonstrate is turning out to be broadly utilized for flood plain display and is an extremely viable device for evaluating flood. Flood propagations can be better understood by simulating the flow and water level by using hydrodynamic modelling. The hydrodynamic flood routing can be recognized by the spatial complexity of the schematization such as $1 \mathrm{D}$ model and 2D model. It was found that most of available hydrological models for flood forecasting are more focus on short duration as compared to long duration hydrological model using the Probabilistic Distribution Moisture Model (PDM). The aim of this paper is to discuss preliminary findings on development of flood forecasting model using Probabilistic Distribution Moisture Model (PDM) for Kelantan river basin. Among the findings discuss in this paper includes preliminary calibrated PDM model, which performed reasonably for the Dec 2014, but underestimated the peak flows. Apart from that, this paper also discusses findings on Soil Moisture Deficit (SMD) and flood plain analysis. Flood forecasting is the complex process that begins with an understanding of the geographical makeup of the catchment and knowledge of the preferential regions of heavy rainfall and flood behaviour for the area of responsibility. Therefore, to decreases the uncertainty in the model output, so it is important to increase the complexity of the model.
\end{abstract}

\section{Introduction}

A flood can be defined as the inundation of a normally dry area caused by an increased water level in a watercourse or in a body of water. Broadly, flooding can be classified as river flooding, coastal flooding, and urban flooding. This study is limited to the floods in rivers, which can be characterised by the sudden or gradual increase in water levels, normally beyond the bank level of the river watercourse and subsequently inundating its surrounding.

Flood disaster occurs quite frequently in Malaysia and has been categorized as the most threatening natural disaster compared to landslides, hurricanes, tsunami, haze and others. A study by JPS entitled National Register of River Basin, 2003 shows that $9 \%$ of land areas in Malaysia are prone to flood which may affect approximately 4.9 million of the population. This may result in a great loss of RM915 million per annum due to economic depletion of approximately RM2 billion in a year. Massive floods have been recorded since 1926 followed by 1967, 1971, 1973, 1970 and 1988. Recently, flood has occurred more frequently particularly in Pulau
Pinang (1998/ 2003), Kuantan (2001/ 2003/ 2013), Kuala Lumpur (2003/ 2007/ 2011), Perlis/ Kedah (2005), Pahang/ Terengganu/ Kelantan (2004/ 2014), Johor Bahru (2004/ 2014), Shah Alam (2006/ 2014), Johor/ Pahang/ N. Sembilan/ Melaka (2006/ 2007/ 2011). In 5 years between 2011 and 2015, a total of 714 floods have been recorded comprising flash flood (556), monsoon flood (147), mud flood (4), flood due to dam release (7) and more than 200 flash floods particularly in 2015. The extreme flood disaster which happened from 14th December 2014 to 10th January 2015 affected 6 states in Malaysia namely Pahang, Terengganu, Kelantan, Perak, Perlis and Johor has led to loss of assets and lives. Further, the flood in Kelantan destroyed 2000 houses with a total loss of assets at RM2.9 billion. It also reported 25 deaths and 500,000 house evacuations.

The Red Flood which occurred in Kelantan back in 1926 recorded with continuous rainfall for 10 days which led to river overflow from Sg. Kelantan flooding Kita Bharu, Pasir Mas and Tanah Merah. After 40 years, heavy rain for 5 consecutive days from 2 nd to 6 th January 1967 has resulted in a massive flood of the same magnitude. It led to 38 deaths and affected approximately

\footnotetext{
${ }^{\mathrm{a}}$ Corresponding author: wanhazdyazad@gmail.com
} 
537,000 (84\%) people in Kelantan. In 2004, another major flood disaster occurred in Kelantan due to heavy rain at $\mathrm{Sg}$. Kelantan river basin affecting Kota Bharu, Pasir Mas and Tanah Merah. Only 10 years later, the 'Yellow Flood' returned to Kelantan and destroyed houses at Kuala Krai and Tanah Merah. The flood overflowed above two-storey schools and covered Kuala Krai town beyond 5 metres. It resulted in 14 deaths, and more than 339,703 people or 87,024 families moved to flood evacuation centres or stayed with nearby family members.

\section{Forecasting Sites and Model}

The two sub-catchments selected in this study which is River Lebir and River Galas located upper of River Kelantan Catchment. Figure 1 gives an overview of the selected sites.

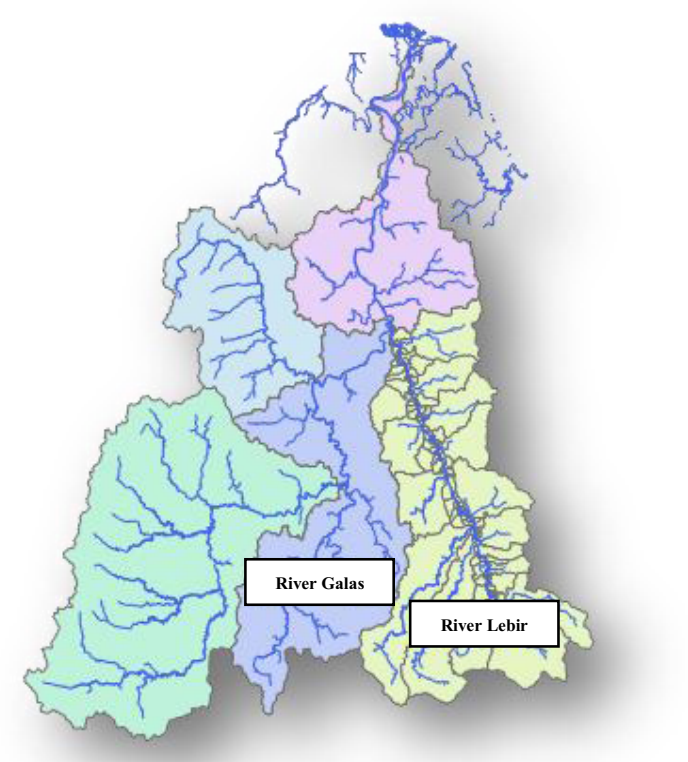

Figure 1. Detail of the locations of selected sub-catchments

\subsection{River Lebir Sub-Catchment}

The River Lebir flows generally in a general north from its main source near Kuala Koh National Park to its confluence with the Kelantan River near Kuala Krai. River Lebir Sub-Catchment is long and narrow, approximately $170 \mathrm{~km}$ and with average of slope $0.09 \mathrm{~m} / \mathrm{m}$. The catchment area is $3,302 \mathrm{~km}^{2}$. The percentage of the imperviousness and pervious area for this catchment area is $0.26 \%$ and $99.74 \%$.

\subsection{River Galas Sub-Catchment}

The main river in this sub-catchment is River Galas with approximately $200 \mathrm{~km}$ flows from Mount Tahan National Park to its confluence with Kelantan River near Kuala Krai. The percentage of the imperviousness and pervious area for this catchment area is $0.87 \%$ and $99.13 \%$. The catchment area is $2,519 \mathrm{~km}^{2}$.

\subsection{Rainfall-Runoff Model}

Rainfall runoff models are characterized by a different level of complexity and data requirement. Thus, selection of rainfall runoff model are depends on how accurate the output is desired. Brocca, Melone, \& Moramarco (2011) stated three main concerns in selecting rainfall runoff model as follows:

(i) Parameter identifiability (uncertainty) where the parameters incorporated in the rainfall-runoff model might increase the model uncertainty

(ii) Physical process description where reliability of the physical processes represented by the model structure is difficult to test and, also, different structures can produce similar results (as with parameters)

(iii) Applicability domain, where many hydrologists suggest choosing models with flexible structures that can be tailored to the 'local' observed conditions.

\subsection{Probabilistic Distribution Moisture Model (PDM)}

Response of the catchments to the rainfall has been modelled using Probabilistic Distribution Moisture Model (PDM). The PDM is a well-established rainfallrunoff model (Moore, 2007). A schematic of its basic processes is provided in Figure 2 and a more thorough description of its formulae and origins is available in (Moore, 2007). The PDM model essentially distributes rainfall between runoff and recharge according to a soil moisture store. The runoff and recharge is routed via stores to the catchment outflow. One of the main advantages of the model is the use of a probability distribution rather than a single value for the soil moisture store. This represents the spatial variability in soil storage across the catchment and prevents threshold type behaviour. The model's short computational run time and continuous soil moisture accounting model makes it suited to the continuous simulation of incoming data for flood forecasting. The model can also use incoming flow gauge telemetry to update its internal soil moisture values in a process known as state correction. This is a powerful tool in ensuring model outputs are tuned to observations where these are available. The PDM model has been integrated into InfoWorks ICM and this includes a calibration suite which allows rapid and user friendly calibration using automated and manual methods with the aid of a number of objective functions and graphs for visual inspection of fit. 


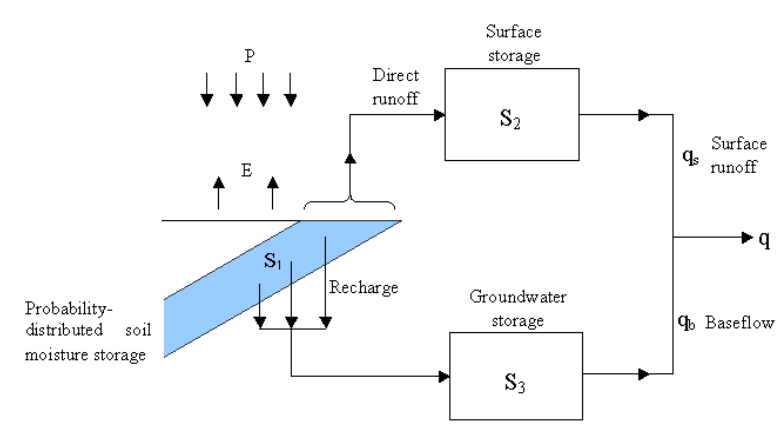

Figure 2. The PDM Rainfall Runoff Model (Moore, 2007)

PDM model was used in this study due to its less complexity. PDM model only considers heterogeneity in the top soil layer has been shown to improve subsequent river discharge when fed into a river routing scheme (Clark et al., 2011). The model is largely used in real-time river modelling systems to properly simulate the catchment hydrologic parameters over long periods of time, which take into account the variation in the depth of soil moisture storage capacity across a catchment, and that the catchment response to rainfall will change as these stores become saturated (Innovyze, 2012)

\subsection{The 2 Dimensional Flood Routing Model}

InfoWorks ICM (Integrated Catchment Modelling) is the first truly integrated modelling platform to incorporate both urban and river catchments. With full integration of $1 \mathrm{D}$ and $2 \mathrm{D}$ modelling techniques both the above- and below-ground elements of catchments can be modelled as never before. InfoWorks ICM enables the hydraulics and hydrology of natural and manmade environments to be incorporated into a single model (Innovyze, 2015).

\section{Approaches and Methodology}

Main components for the development flood forecasting model are:

- Hydrological component

- Hydrodynamic component

\subsection{Hydrological Component}

The Lebir and Galas catchment has a humid tropical climate and the average annual rainfall for Peninsular Malaysia is 3,000 mm (DID, 2014), although seasonal distribution of rainfall varies widely from place to place. Lebir and Galas catchment is highly forested with a mixture of some remaining areas of primary rainforest and managed agricultural plantations. Historically, the catchment was almost completely forested, until significant conversion to rubber plantations and palm oil plantations from the 1960s onwards. Since that time, flooding has become more common and severe. Furthermore, urbanisation is spreading, and in combination with the effects of necessary deforestation, soil erosion and flash flooding are becoming more prevalent.

\subsubsection{Hydrological Model}

The Soil Conservation Service Unit Hydrograph Method (SCS UHM) hydrological model is an event-based model and is unsuitable for flood forecasting where the soil moisture must be tracked continuously. Suitable method for flood forecasting hydrology using a combination of these models:

- $\quad$ Probability Distributed Model (PDM)

- $\quad$ Simple Runoff Model (SRM)

For larger sub-catchments, having reasonable amounts and quality of historical calibration data (concurrent rainfall and flow data), the PDM is the best choice to be run within InfoWorks ICM. For smaller sub-catchments, with fewer calibration data, the SRM is the best choice. Minimal amounts of historical flow data were available for model calibration. Historical level data were available, but these require rating equations to convert the level data to flow data.

Figure 3 to 5 shows the available hydrological data.

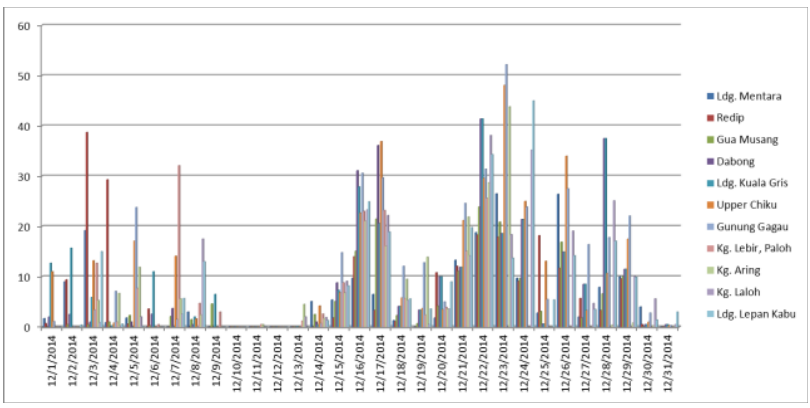

Figure 3. Available Rainfall Data for 2014 Flood Event

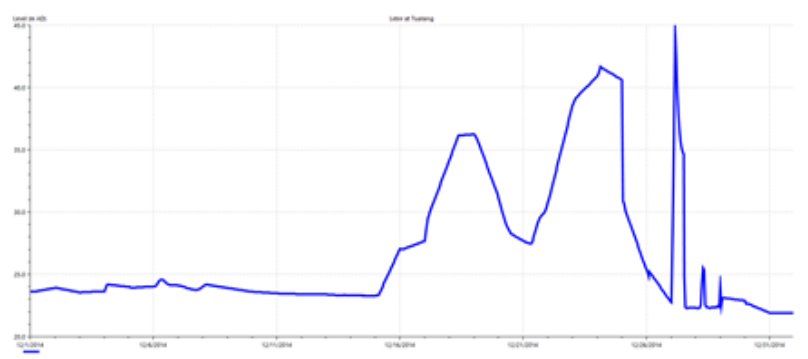

Figure 4. Overview of gauged hourly water level time series data for Lebir water level station (December 2014)

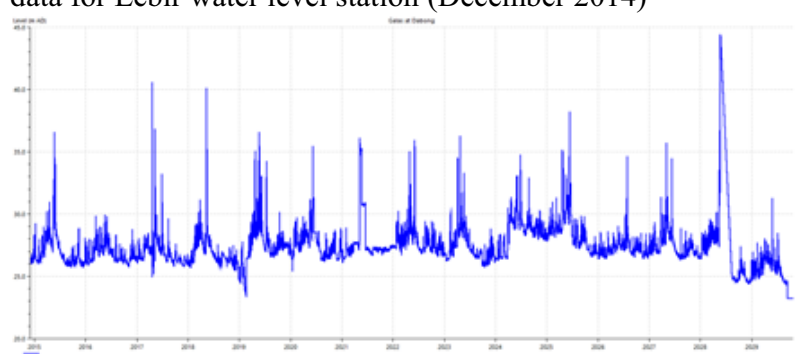

Figure 5. Overview of gauged hourly water level time series data for Galas water level station (December 2014) 


\subsection{Hydrodynamic Component}

The purpose of carrying out the flood routing analysis is to simulate flood parameters such as flood water depths, flow velocities, flood extent and flow propagation.

In preparing the hydrodynamic flood forecasting model, integrated use of 1 dimensional (1D) and 2 dimensional (2D) hydrodynamic models is utilised to simulate the river and the flood plain interaction. The $1 \mathrm{D}$ model is used for water level assessment along the axis of the water body. In generating flood flows at the floodplains, which requires more complex computations, a 2D model is used.

\subsubsection{Governing Equations}

The basic equations used in most of the 1D Hydrodynamic Models are based on the one-dimensional unsteady state gradually varied flow equations, which are termed as the 'St. Venant equations';

- the mass conservation / continuity equation:

$$
\frac{\partial Q}{\partial x}+\frac{\partial A}{\partial t}=c
$$

- the momentum conservation or dynamic equation:

$$
\underbrace{\frac{\partial Q}{\partial t}}_{(I)}+\underbrace{\frac{\partial}{\partial x}\left[\frac{\beta Q^{2}}{A}\right]}_{(I I)}+\underbrace{g A\left[\frac{\partial h}{\partial x}-S_{0}\right]}_{(I I)}+\underbrace{g \frac{A Q|Q|}{K^{2}}}_{(I V)}=0
$$

Where:

$$
\begin{aligned}
& Q(x, t)=\text { discharge }\left(\mathrm{m}^{3} / \mathrm{s}\right) \\
& t \quad=\text { time (s) } \\
& x \quad=\text { streamwise direction }(\mathrm{m}) \\
& c \quad=\text { lateral inflow per unit length of flow } \\
& A(x, t) \quad=\text { cross-sectional area }\left(\mathrm{m}^{2}\right) \\
& g \quad=\text { gravitational acceleration }\left(\mathrm{m} / \mathrm{s}^{2}\right) \\
& h \quad=\text { water level }(\mathrm{m}) \\
& \text { So }=\text { bed slope }(\mathrm{m} / \mathrm{m}) \\
& K=\text { conveyance }\left(\mathrm{m}^{3} / \mathrm{s}\right) \\
& \beta \square \quad=\text { Boussinesq coefficient }
\end{aligned}
$$

and

$$
\begin{aligned}
& \text { I. local acceleration term } \\
& \text { II. } \\
& \text { convective term (responsible for non- } \\
& \text { linearity of equation) } \\
& \text { pressure term due to change in depth } \\
& \text { over reach - if } S o \text { is neglected, then } \\
& d h / d x \text { approximates the friction slope } \\
& \text { based on the change in water level } \\
& \text { source/gravity term causes water to } \\
& \text { flow }
\end{aligned}
$$

In some instances, Equation 1 is set equal to $\mathrm{c}(x, t) \mathrm{m}^{2} / \mathrm{s}$, which is equivalent to specifying lateral inflows from small rivers. Underground sources and ground water can influence the lateral inflow and this directly influences the calculation.
The assumptions inherent in the application of Equation 1 and Equation 2 are:

i. the flow is one-dimensional i.e. a single velocity and elevation can be used to describe the state of the water body in a cross-section;

ii. the water is incompressible with a constant density $\left(=1000 \mathrm{~kg} / \mathrm{m}^{3}\right)$ uniformly distributed;

iii. the bed slope is small;

iv. the streamline curvature is small and vertical accelerations are negligible, hence the pressure is hydrostatic;

v. the effects of boundary friction and turbulence can be accounted for by representations of channel conveyance derived for steady state flow; and

vi. all functions and variables are continuous and differentiable;

In the modelling of floods, flows often take short cuts through flood plains where the 1D description may become quite inaccurate. This is even more the case for dam or embankment failures, where the flow may leave the flood plain completely and inundate natural terrains. For this reason the 2D shallow water equations are introduced. Following the same principles as for 1D flow, the mass conservation / continuity equation reads as below (Equation 3):

$$
\frac{\partial h}{\partial t}+\frac{\partial(u h)}{\partial x}+\frac{\partial(v h)}{\partial y}=0
$$

Where, the $\boldsymbol{y}$ axis, orthogonal to the $\boldsymbol{x}$ axis, is introduced with its flow velocity $\boldsymbol{v}(\mathrm{m} / \mathrm{s})$ associated to it. The convective momentum terms are subject to the same principles as discussed for the $1 \mathrm{D}$ approximation.

\subsubsection{Numerical Solution}

Numerical solution in a 2D model depends on the selection of the grid types. The example of grids are flexible mesh, rectilinear grid and curvilinear as shown in Figure 6.

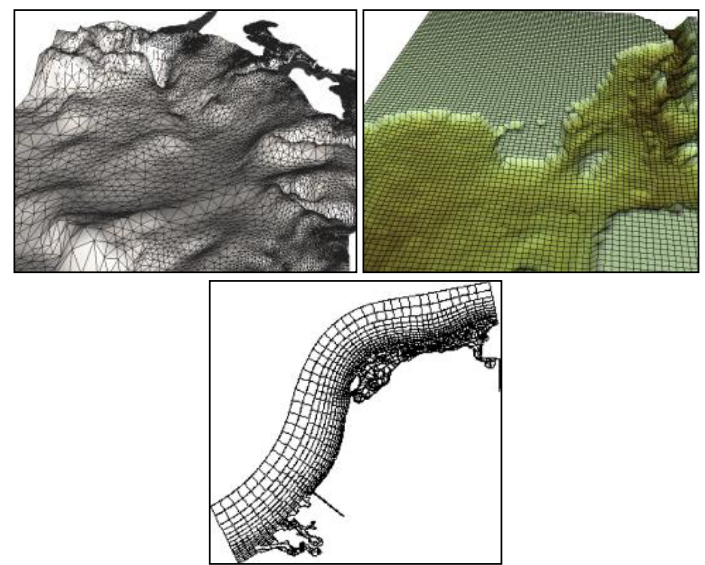

Figure 6. Example of types of grids for numerical solution in 2D model (flexible mesh, rectilinear grid and curvilinear) 
Flexible mesh and rectilinear grid are usually applied for floodplain modelling. The general characteristics of these grids are as follows:

i. $\quad$ Flexible Mesh - Refer to Figure 7

- Cell-centred finite volume method

- Unstructured mesh

- Triangular and quadrilateral elements

- Spherical and Cartesian coordinates

- Explicit up winding scheme limits time step for stability

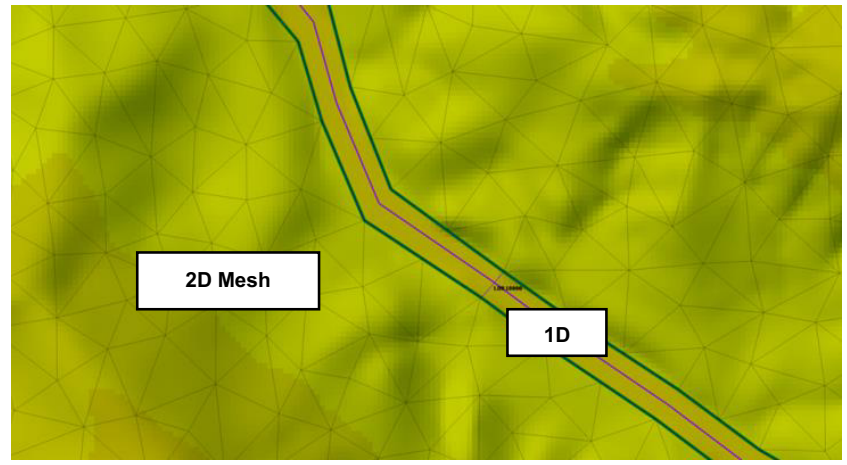

Figure 7. Example of Flexible Mesh used in this study

\subsubsection{D/2D Hydrodynamic Model Development}

The flood plain shall be modelled using 2D modelling with mesh technique. For 2D modelling, flow is not constrained to follow the direction specified by the modeller as in 1D modelling, but is allowed to spread freely over the ground surface under the influence of gravity. The modelled area is represented by a $2 \mathrm{D}$ mesh of calculation elements. The InfoWorks ICM engine uses a finite volume technique which takes advantage of unstructured meshes. The engine is fully integrated within the InfoWorks GUI and so benefits from the full range of data import, validation, version control and audit trail functionality.

2D finite volume methods are used to solve the shallow water flow equations, using the Riemann solver with a TVD shock capturing model that makes it particularly suitable for rapidly varying flood flows associated with bank overtopping or breaching. The $2 \mathrm{D}$ engine runs simultaneously with the $1 \mathrm{D}$ engine allow for a time step by time step exchange of water between the each zone. This ensures that there is feedback between the two simulations. Links between the $1 \mathrm{D}$ and $2 \mathrm{D}$ zones can either be lateral i.e. 1D channel and 2D floodplain or inline, i.e. a $1 \mathrm{D}$ reach that feeds in to a $2 \mathrm{D}$ reach or vice versa. Each model network can have multiple 1D and 2D zones. Key to the efficiency and ease of use of the 2D engine is the automatic generation of the computational mesh. The mesh generator includes functionality to control the resolution by both maximum triage area and or minimum triangle angles. These can also be varied for differing parts of the mesh to enable high resolution to be maintained around key features, while using lower resolution for flatter, featureless, less important regions. In addition the $2 \mathrm{D}$ engine offers thematic mapping of the velocity vectors using either direction arrows whose length indicates the magnitude of the velocity coloured contouring.

\section{Results and Discussion}

\subsection{PDM Calibration}

The upstream boundary of the InfoWorks ICM model is at the location of the Lebir at Tualang water level gauge. A PDM model was defined for this sub-catchment. This PDM model will have a substantial impact on the overall performance of the flood forecasting system; it was therefore important to achieve the best calibration possible with the available data. The following steps were undertaken:

i. Quality control of gauged rainfall and gauged water level data;

ii. Analysis of correlations between rainfall and river water levels;

iii. Data selection for the PDM calibration; and

iv. Calibration of the PDM model.

From the quality control process of the data it was clear that there were continuous level time series available for model calibration. In addition, there were data for 11 rainfall gauges which might not all be equally relevant to the calibration of selected events due to the spatial variation of the rainfall. In order to get a good PDM calibration, there would need to be a high correlation between level and rainfall. In Dec 2014 there was a high correlation between river level and rainfall on a monthly basis. The PDM model was calibrated for this time period. The Lebir catchment is a fast responding system. The calibration approach was therefore to consider the following parameters and develop appropriate values for them given the catchment characteristics and the likely hydrological response. The parameters adjusted during the calibration are described below.

a) Rainfall and evaporation

i. rainfac - Rainfall factor, from observed rainfall to effective rainfall.

ii. be - Exponent in actual to potential evaporation rate function, affects variation between seasons.

b) Moisture Storage Distribution

i. cmin - Minimum moisture store capacity.

ii. cmax - Maximum moisture store capacity.

iii. b - Exponent of store capacity distribution function controlling spatial variability of store capacity.

c) Recharge and Runoff

i. $\mathrm{Kg}$ - Groundwater recharge time constant, controls rate of aquifer recharge. 
ii. St - Soil tension storage capacity, increase to prevent complete drainage of soil moisture store.

iii. $\mathrm{Bg}-$ Exponent of recharge function, increase to magnify sensitivity of recharge rate to soil dryness.

d) Surface flow

i. k1 - Time constant of surface flow storage for first linear reservoir.

ii. k2 - Time constant of surface flow storage for second linear reservoir.

e) Baseflow

i. $\mathrm{kb}$ - Base flow time constant, controls length of recession.

f) Time and flow

i. tdly - Time delay, shifts hydrograph horizontally along time axis.

ii. qconst - Constant flow representing return/abstractions, shifts hydrograph vertically along the flow axis.

The preliminary calibrated PDM model performed reasonably for the Dec 2014, however, it underestimated the peak flows. Result of the PDM calibration is presented in Figure 8. In this figure, the blue trace is the observed flow and the green trace is the PDM modelled flow. This result showing a reasonable goodness-of-fit (R2) between the model results and observed flows of 0.68 . The $\mathrm{R} 2$ values vary considerably, and this reflects the nature of the data and the spatial location of the gauges relative to the spatial coverage of the flood event. For example, one event may be well recorded be a particular gauge and less well recorded by another gauge situated further away.

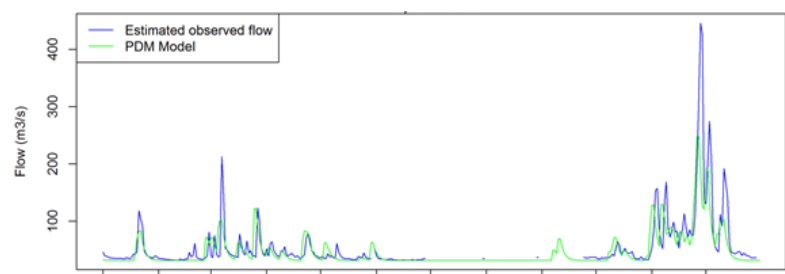

Figure 8. Preliminary PDM Calibration Result December 2014 $\left(\mathrm{R}^{2}=0.68\right)$

\subsection{Soil Moisture Deficit (SMD)}

The soil moisture deficit (SMD) time series has been calculated using PDM. SMD is the depth of rainfall which would be required to bring the catchment to saturated conditions. Figure 9 shows the SMD and Runoff for December 2014 flood event. The orange trace is the SMD, the green trace is the runoff, and the black bar is the hyetograph. From this result soil moisture storage are set to zero and produce more runoff. During the SMD at zero, the soils became saturated and cause the flooding.

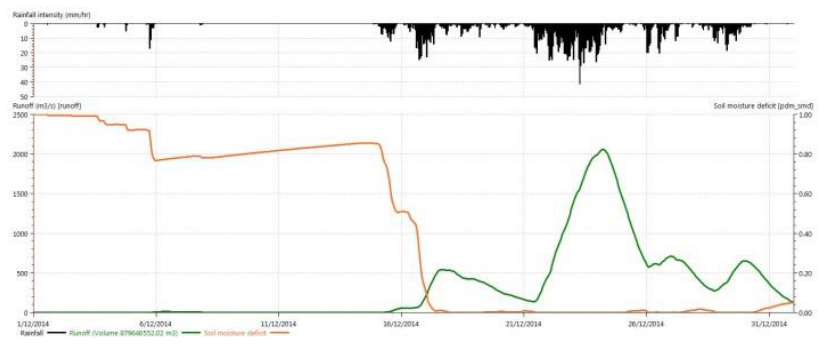

Figure 9. SMD and Runoff for Lebir Catchment

\subsection{D Flood Plain Representations - Mesh Polygon}

Flood plain is represented by $2 \mathrm{D}$ polygon contained the definition of the mesh. The information includes the mesh size and roughness. The elevation for each mesh is taken from the ground model either from IFSAR. The connection between the main river and the flood plain is through the bank line. If the geometry is complex such as valley, then another polygon can be specify with finer mesh. As a start for this study, River Galas and River Lebir maximum mesh size of $20,000 \mathrm{~m} 2$ and minimum mesh size of $4,000 \mathrm{~m} 2$ has been applied. The preliminary Flood inundation area is shown in Figure 10.

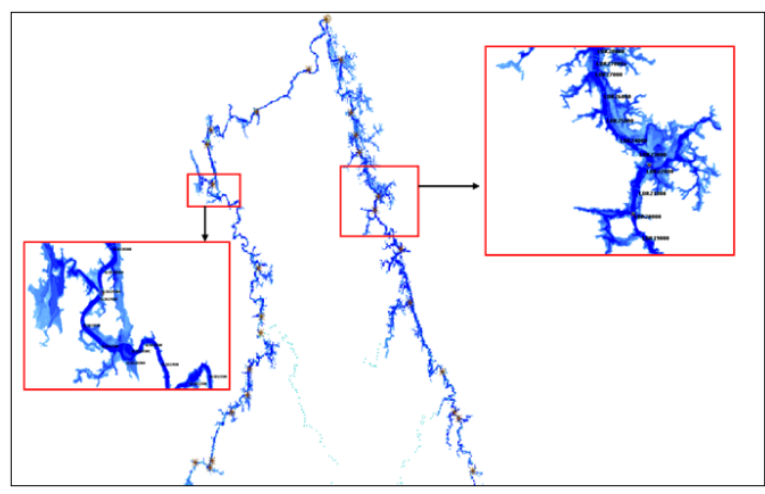

Figure 10. Preliminary Flood Hazard Map for Dec 2014

\section{Future Works}

Results presented in this paper are still at early stage. The ultimate contribution of this study is flood disaster warning dissemination to related agencies and community at risk. In order to achieve the study objectives, the following are planned to be performed near future:

(i) Production of flood trend analysis based on one selected event at particular area of interest.

(ii) Identify flood forecast lead time for particular area of interest in River Kelantan Catchment.

(iii) Development of Flood hazard map for River Kelantan Catchment using 2D mesh method to identify the critical area. 


\section{Conclusions and Recommendation}

Calibration of the PDM for this study is not a straightforward process. The Pareto distribution of soil storage depths has been found to provide a simple yet flexible description of soil moisture storage for Lebir and Galas Catchment. SMD is essential to understand the correlation between the rainfall and runoff. This would give an advantage to the flood forecasting model using PDM which is the long duration hydrological model should be the first choice.

Two dimensional flow models have been progressively utilized as a part of flood modelling and are giving an important device in the appraisal of stream ways and along these lines the receptors of flooding. In this case, 2D hydrodynamic flood modelling is impressively produce the flood inundation area and flood propagation and this made modeller to have better understanding flood behaviour in this study area. This prompts an exchange off between the run time of the 2D model and precision of the model at speaking to the $2 \mathrm{D}$ surface. Bigger size of mesh components permit models to run all the more rapidly however may not accurately speak to every one of the elements of the surface. Frequently the full detail of the hidden geography is not representing in the hydrodynamic flood model. Generally 2D hydrodynamic flood model contain either a structured grid or an unstructured mesh to represent the ground topography. Unstructured mesh have the favourable position that triangle sizes can differ within the mesh, permitting the modeller to create a better work in territories obliging point by point examination and a coarse mesh in general to accomplish sensible keep running times. The ideal $2 \mathrm{D}$ mesh will represent the $2 \mathrm{D}$ topography with adequate precision to give trust in model results while keeping up a sensible run time. The exploration in this proposition speaks to a preparatory study to focus the impact that the discretization of the geography can have on the hydrodynamic flood model results gave by flood analysis model.

Due to complexity of overland flow analysis, 2D hydrodynamic flood model provides better understanding on the flood behaviour of the study area. This study aims to produce of flood trend analysis and provide information on flood forecast lead time for particular area of interest in River Kelantan Catchment. Finally, the model output will provide flood early warning dissemination to the public at risk, including identification of critical area through flood hazard map for River Kelantan Catchment using 2D mesh method.

\section{References}

1. Brocca, L., Melone, F., \& Moramarco, T. (2011). Distributed rainfall-runoff modelling for flood frequency estimation and flood forecasting. Hydrological Processes, 25(18), 2801-2813. http://doi.org/10.1002/hyp.8042

2. Garcia-Navarro P. and Brufau P., Numerical methods for the shallow water equations: 2D approach, in Donald W Knight and Asaad Y. Shamseldin (Eds.), River basin modeling for flood risk mitigation, (pp. 409-428), Taylor \& Francis. (2006).

3. Clark, D. B., Mercado, L. M., Sitch, S., Jones, C. D., Gedney, N., Best, M. J., ... Cox, P. M. (2011). The Joint UK Land Environment Simulator (JULES), model description - Part 2: Carbon fluxes and vegetation dynamics. Geoscientific Model Development, 4(3), 701-722 http://doi.org/10.5194/gmd-4-701-2011

4. Clark, D. B., Mercado, L. M., Sitch, S., Jones, C. D., Gedney, N., Best, M. J., ... Cox, P. M. (2011). The Joint UK Land Environment Simulator (JULES), model description - Part 2: Carbon fluxes and vegetation dynamics. Geoscientific Model Development, 4(3), 701-722. http://doi.org/10.5194/gmd-4-701-2011

5. Department of Irrigation and Drainage. Laporan Banjir Tahunan Jabatan Pengairan dan Saliran, Malaysia. (2015).

6. Environmental Agency. Comparison of RainfallRunoff Models for Flood Forecasting. R\&DTechnical Report W241. (2001).

7. Gutierrez, J. et al. in prep. Testing and application of a practical new 2D hydrodynamic. Flood Risk 2008 Conference, Oxford, 30th September-2nd October 2008.

8. Hunter, N. M., Bates, P. D., Neelz, S., Pender, G., Villanueva, I., Wright, N. G., Liang, D., Falconer, R. A., Lin, B., Walle, S., Crossley, A. J., Mason, D. C.Benchmarking 2D hydraulic models for urban flooding, Proceedings of the ICE - Water Management, Volume 161, Issue 1, pages $13-30$. (2008)

9. Innovyze. Technical Paper. Innovyze Ltd Howbery Park, Wallingford, Oxfordshire, OX10 8BA, United Kingdom. (2015).

10. Innovyze. (2012). Real - Time Operational Forecasting, Warning \& Reporting FloodWorks Technical Review.

11. Price R.K. and Vojinovic, Z., Urban Hydroinformatics: Data, Model and Decision Support for Integrated Urban Water Management, IWA Publishing. (2011).

12. R.J. Moore., The PDM Rainfall Run-off Model. Journal of Hydrology and Earth System Science, 11 (1), 483-499. (2007).

13. Rosenthal, U., Hart, P. and Beyuzen, M. Flood Response and disaster management: a comparative perspective. In Flood Response and Crisis Management in Western Europe, Rosenthal, U. and Hart, P. (eds.), Springer-Verlag Berlin Heidelber, pp.1-13. (1998).

14. Schmitt T.G., Thomas M. and Ettrich N. Analysis and modeling of flooding in urban drainage systems. J. Hydrology, 299(3-4), 300-311. (2004).

15. Vojinovic Z., Bonillo J., Kaushik C. and Price R. Modelling flow transitions at street junctions with 1D and 2D models. 7 th Int. Conf. on Hydroinformatics, Nice, France, Vol. I, 377-384. (2006). 